\title{
How to Boost your App Store Rating? An Empirical Assessment of Ratings for Mobile Banking Apps
}

\section{Anuj Pal Kapoor ${ }^{1}$ and Madhu Vij ${ }^{2}$}

\author{
1 University of Delhi, Faculty of Management Studies, Delhi, India, anuj.kapoor phd@fms.edu \\ 2 University of Delhi, Faculty of Management Studies, Delhi, India, drmadhuvij@fms.edu
}

Received 24 August 2018; received in revised form 28 February 2018; accepted 6 March 2019

\begin{abstract}
Smartphones have become the colossal point of attention for both individuals and businesses worldwide resulting into a whole level of new and innovative experience in mobile computing. Mobile applications (mobile app) is an upshot of such innovative mobile computing and produces a noticeable change in the way humans feel and experience. Each and every mobile app has a rating attached to it on App store, which measures the overall feedback of users for a particular mobile app. The present research develops a theoretical research model as a framework to identify the key decision factors influencing Indian users to rate mobile banking apps. A mix method approach consisting of qualitative interviews and a self-administered survey was used to gather information from 343 respondents in Delhi, India. The empirical analysis identifies and ranks six important decision factors: login time, visual design, navigational design, information design, collaboration and service quality, influencing the ratings of a mobile app. This study is one of the very few that has attempted to investigate the relationship between mobile app attributes and user ratings for retail banks and for providing new insights into mobile app attributes of retail banks and their effects on user ratings.
\end{abstract}

Keywords: Mobile banking, Mobile applications, App ratings, Logit regression analysis, India 


\section{Introduction}

In the early 2000's, the application of third generation (3G) mobile communication technologies triggered mobile commerce development across the world. Subsequently, the switch from feature phones to smart phones begun and the adoption of smart phones was embraced globally. According to [20], there will be more than three billion Smartphone users, or one-quarter of the global population, by 2020. In India, the e-commerce market is expected to grow to US $\$ 200$ billion by 2020 due to the rise in Smartphone penetration and the launch of $4 \mathrm{G}$ networks along with increasing consumer wealth. According to a report [52], Smartphone penetration in India reached $32 \%$ as of Nov 2017.

A unique trend which has picked up with the introduction of smart phones is the mobile apps. In simple words, a mobile app is a software application developed specifically for use on small, wireless computing devices, such as smart phones and tablets, rather than desktop or laptop computers. The rapid adoption of smart phones and subsequent development of mobile applications (app or apps hereafter) have been changing the ways in which customers interact with a brand. India is the world's fastest growing market for mobile apps [1]. Over 6 billion apps have been downloaded in India [52] and account for more than $50 \%$ of time spent on digital media [40], suggesting that apps have deeply penetrated into the daily lives of Smartphone users. With the development and growth of the Internet and e-commerce, the user-generated data have also dramatically increased [9]. The most common and used use-generated data are the opinions/feedback given by users [29], becoming one of the cornerstone of the success of e-commerce [16]. For that reason, handling and consumption of this type of information has become one of the main focuses of expert systems [8] and, specifically, in On-line Review Systems or Ratings [21]. As these reviews play an increasingly important role in the decision making process when consuming or buying a product, and as more and more information is made available on-line, identifying and locating appropriate entities to consume (e.g. banking, hotels, movies, etc.) has become an even more complex and difficult task for the users. Consequently, mobile app ratings have become a popular tool for filling this gap.

Mobile stores (Playstore in case of Android; App Store in case of ios) enable users to search for, purchase and install mobile applications and then give feedback in the form of reviews and ratings [45]. A review might contain information about the user's experience with the app and opinion on it, feature requests and bug reports. Hence, ratings are valuable not only to users who would like to find out what others think about an app, but also to developers and software companies interested in customer feedback. User ratings and reviews are user-driven feedback that may help improve software quality and address missing application features [45].

Today, with the aid of mobile apps, everything can be practically purchased online, from daily grocery to flights or hotel bookings, banking online or even buying a house. As per a report titled "Encashing on Digital" [3], India currently has around 45 million mobile banking users, as compared to 0.01 million in 2010, showing a growth of around $450 \%$. This rapid growth raises interest in academia and turns mobile app into an attractive field of research. This trend of mobile banking indicates a remarkable potential to the banking industry. Financial Institutes have welcomed mobile apps as an additional communication channel to attract new customers and increase brand loyalty among existing ones [60]. They have realized that customers use a variety of app features to perform diverse tasks such as balance checking, money transfer, online payments, online investments and service requests to name a few. Therefore, companies have started to use apps to increase brand awareness and enhance brand experience, resulting in higher sales [60]. Various banks offer mobile apps with multiple functionalities to their consumer; however all of them differ when it comes to user ratings.

App ratings for banking institutions have a strong influence on how the app of a particular bank ranks in app store search results. Let's assume, we have two banks i.e. bank $X$ and bank $Y$. If the mobile app rating of bank $X$ is higher as compared to bank $Y$, mobile app of bank $X$ will always appear at the top in the app store. Having good reviews and ratings in an app store help drive organic rankings for mobile app and is also crucial in impressing potential user. The more ratings you have for your app, the better chance you have to get discovered and downloaded. When you search for a keyword in Google Play Store what you get as the search result is your App Icon, App Name, and Ratings. This means that ratings in Play Stores directly contribute to the conversion. In Indian context, users can download mobile app for any bank irrespective of whether the individual has an account with that particular bank. When a user has an option of choosing a particular mobile banking app from over hundreds of mobile banking apps, the app store ratings plays a significant role, in deciding which mobile banking app to choose. App ratings play an important role both in determining the likelihood of a potential user to download the app, and as well as reflection of current user satisfaction with the app and bank's service.

There are plenty of attributes for a mobile app, which influences ratings provided by a consumer. The major contribution of this study is to provide an improved understanding of the factors that influence the ratings given by users on Playstore in case of Android and Appstore in case of Apple ios. A vast majority of the prior literature surrounding the intersection of consumers and mobile apps has focused primarily on consumers' initial acceptance or adoption of the technology. For example, researchers have previously used established frameworks such as the Technology Acceptance Model (TAM) [18] to identify what factors lead consumers to initiate using a particular type of 
technology. Most of the modest research on mobile apps, specifically, centers on antecedents of consumers' initial app adoption [46].

Hence, we aim to differentiate our research from prior work, in part, by moving beyond drivers of initial app adoption. Our goal is to explore consumers' ratings for adopted apps; and analyze the association between mobile app attributes and mobile app ratings. This paper addresses such limitations and examines the mobile app attributes and analyze customer rating for these attributes for banking institutes in India. Our research offers two substantive contributions; first by linking mobile app attributes with ratings, this study provides quantified evidence that shows how attributes of a mobile app impacts customer ratings; second, to expand our understanding of how the use of interactive technology influences usage behavior. Given the issues of using self-reported measures of mobile app use [4], our study adds to the mobile marketing literature by incorporating behavioral measures of app ratings.

To explore the role of mobile app in consumer engagement, the current study developed and empirically tested a model to examine how mobile app attributes influence the mobile app ratings for a consumer. The study focuses on six key attributes - login time, visual design, navigational design, information design, collaboration, service quality and identifies their effect on user ratings. Five of the constructs i.e., visual, navigational, information, collaboration and service quality have been adapted from previous studies whereas the sixth construct, login time is a result of the pre study. Login time basically refers to the time; a particular user takes to login to the mobile app for a particular bank. For example, while login-in to Housing Development Finance Corporate (HDFC) Bank, a user is suppose to key in the customer ID, followed by password and then checking the profile picture. When information from all the three stages matches, a user logs in to the mobile app, whereas in case of Citibank, the user keys in the username and password and logs- in. There are banks, which only asks for a unique ID and with the help of an OTP (One time password) login to the mobile app is possible. The login time varies across banking institutes and thus becomes an essential attribute for a mobile app.

The specific objectives of the current research are:

- To develop a comprehensive theoretical research model as a framework to analyze the decision factors for rating mobile banking apps in India

- To identify the factors that influence Indian consumers' decisions to rate a particular mobile banking app

- To determine the order of importance of the factors that impact ratings for mobile banking apps, on Indian consumers' choices

The information on the decision factors and their relative importance obtained from the comprehensive empirical analysis will benefit future researchers studying consumer behaviors in the mobile banking industry. In particular, researchers who are interested in India's growing mobile banking market will be benefited. The remaining part of this research paper is organized as follows; section 2 contains the theoretical explanation of the hypotheses considering current research findings; section 3 explains the pre study; section 4 explains the conceptual framework guiding the study and section 5 explains the method employed. The results of the study are presented and discussed in Section 6. Section 7 concludes the documented research with limitations along with future scope.

\section{Literature Review \& Hypothesis Development}

There exist quite a number of studies on app ecosystem [10] and online rating and reviews [21]. As these reviews play an increasingly important role in the decision making process when consuming or buying a product, online. These studies have elicited user's preferences through numerical ratings for a particular service or product. One of the first studies, in the field [14] analyzed the features extracted from app descriptions and their relationship to nontechnical information. Previous studies have captured users' preferences by means of numerical reviews (ratings) for products or services, where users have to map their internal preferences to numerical ratings. These ratings are usually coupled with some textual information that enables users to provide additional comments and complete their reviews [9]. Earlier work on customer reviews [24], examined the customer reviews for e-commerce website (Site 1) and its related data mining techniques. Another study [24], proposed different approaches; to map textual review to numerical ratings.

Limited studies have examined the consumer's interest in the attributes of mobile apps and whether the attributes influences the ratings of a mobile app? Some of the relevant research suggests that mobile app attributes are critical external stimuli triggering individual's internal cognitions and emotions [10], [12], [32], [39], [47]. In fact, [10] asserted that three domains of technology product attribute trigger approach-avoidance behavior: product appearance (visual appeal), product performance (usefulness, ease of use, navigation, and innovativeness of technology) and product communicative power (self-expression, information). What makes a mobile app powerful is its interactive nature that allows users to experience the brand through the mobile app attributes [2], [7], [38], [41], [58]. Mobile app attributes cause certain psychological reactions based on the visual and information attributes of a mobile app [47]. User interface attractiveness such as visual and navigation designs were identified as important attributes which enables 
users to use a particular mobile app [34]. In case of mobile app of retail banks, information such as account balance, historic statements, purchase history and investments etc. are part of the information design.

Previous studies have also described consumers' ratings and reviews for mobile apps but fewer studies have examined app ratings for mobile banking apps, used in the context of everyday choices about transacting over the internet. Given the fact that limited empirical studies are available to understand customer feedback in terms of ratings and reviews for mobile apps, it is necessary to extend the extant literature by proposing a research model to elucidate what and how mobile app attributes affects users' feedback and result into higher or lower ratings.

\subsection{Mobile App Attributes and Influence on Ratings}

In this section, we develop the arguments for the research model (Figure 1) and hypothesis. The mobile app attributes identified by prior literature have been discussed along with their influence on mobile app ratings. The identified attributes are (1) Visual design, (2) Information design, (3) Navigational design, (4) Collaboration design, (5) Service quality and (6) Login time, along with dependent variable i.e app ratings.

\subsubsection{Visual Design}

A growing body of literature has identified distinctive characteristics of mobile devices and discussed their implications. Visual design is one of the most important attribute of a mobile app [34], [44]. The visual design of a mobile app refers to its consistency, aesthetic, and the attractiveness of the website's appearance including images, colors, fonts, shapes, animations, and layout [10], [17]. Visual designs influence users to a great extent while using a mobile app for online purchases [20], [32]. Visual design includes the overall look and feel of the mobile app interface, colors and fonts used, etc. Visual design is a key component of website quality [19] [55] and affects users' experiences while using and interacting with the site [57]. According to a study [53], attractive visual website design sends positive messages to consumers about the quality of the product and the vendor. Better visual designs with an app will lead to a higher level of users' engagement [11]. In a study [50], it was observed that respondents are hesitant to engage with a mobile app which has poor visual appeal. Another researcher [32], confirmed that visual and information attributes of a mobile app are associated with acceptance of mobile apps. A framework was proposed [10], for mobile attributes, which influence customer propensity to adopt mobile apps and also results in engaging experience. Accordingly, visual design was included as the app attributes since it influences a consumers' engagement with a mobile app and resulting into a positive ratings. Therefore the following hypothesis is proposed:

\section{H1: Visual design has a positive influence on the mobile app ratings for mobile banking apps in India.}

\subsubsection{Information Design}

In [47], it was argued that amount on information available increases the engagement of users with mobile apps as they provide all the relevant information to the users. A field study [30] also suggested that amount of information and structure of information in mobile apps, influences users to a great extent enhancing their loyalty towards the brand. A mobile app's information design refers to the apps' ability to deliver relevant, current, and easy to understand information to its users [36]. In case of mobile banking, online transactions involve substantial amounts of information related to products, services and payment [47], the availability of sufficient and relevant information increases trust in online transactions and enhances usage intention. In [11] identified amount of information available for the user about a particular service or product on a mobile app as an important attribute. In case of retail banks, account statement, investment decisions, payment history, historic statements and customer touch influence consumers' ratings to a great extent. Thus, the availability of necessary information and the ease of finding and accessing this information can enhance consumers' decision making and purchasing tasks [36]. In contrast, when consumers are exposed to information that may not be relevant or helpful to the task they want to perform, they become dissatisfied and feel irritated because of the time and cognitive effort and resources that they spent in processing the information [49]. Therefore, an efficient and helpful mobile app information design is expected to result in a high rating. Based on the literature, we propose the following hypothesis:

\section{H2: Information design has a positive influence on the mobile app ratings for mobile banking apps in India.}

\subsubsection{Navigational Design}

The navigational design of a mobile app refers to the organization and structural layout of the pages and content. An app's navigation design has a significant impact on the amount of effort required for a user to navigate or use the app [55]. Thus, an efficient navigational design of a mobile app should provide an easy to use navigation control that allows users to go to the desired pages easily and quickly from anywhere in the app, use the appropriate filters as per their requirements with minimal amount of effort [42]. Online consumers prefer simple and direct navigation design that saves them time and effort in finding what they look for and helps them complete purchase transactions with a minimum number of steps. Navigational design was identified as an important attribute while using mobile apps [10]. Navigation design enables user to navigate through the mobile pages seamlessly, be it scrolling through the menu or multiple links within apps or making the payment on the payment gateways. An uninterrupted experience on the mobile app is preferred by users and increases the usage for a particular mobile app. Speed of 
mobile apps and navigational design are conceptualized as important usability measures, resulting in higher conversion [57]. Therefore, we hypothesize that:

H3: Navigational design has a positive influence on the mobile app ratings for mobile banking apps in India.

\subsubsection{Collaboration Design}

Collaboration refers to the alliances between organizations of dissimilar products and services [33]. For example, alliances between Zomato (Online Food Aggragator) and Uber (Cab service provider) are an example of collaboration in the e-commerce ecosystem in India, wherein when a reservation is made at any of the restaurants through the mobile app of Zomato, the user is prompted with a message that an Uber is 5 min away, get instant 15\% off on your ride. Similarly, alliances between HDFC bank, Site 2 and Site 3 are examples of collaboration in the banking space. Whenever a purchase is made on Bookmyshow (India's largest online ticket company) through PayZapp (HDFC banks mobile app), the user gets an instant $15 \%$ cash back to their mobile wallets. Users in India are very particular when choosing mobile app for a particular retail bank. They prefer banks, which has the highest alliances among the e-commerce players in India and provides cash back or instant discount on online shopping, online transactions etc. Therefore, we hypothesize that:

\section{H4: Collaboration design has a positive influence on the mobile app ratings for mobile banking apps in India.}

\subsubsection{Service Quality}

Service quality in e-commerce relates to customers' perceptions of the result of the service and perceptions of service recovery [15]. E-service quality is the overall evaluation and judgment of the quality of service, provided by online companies [51]. In case of mobile banking, service quality can be referred to as online chat service provided by the retail bank, online requests such as cheque book issue or PIN generation and multiple touch points, which connect a consumer with the bank such as online support, e-mail service, online requests, query and grievance handling etc.

In a study, the e-service quality attributes were examined [59] and showed that reliability and security are the two most important attributes under e-service quality. In another study [36], it was found that good service quality, in the context of internet retailing, positively influences the attitude of consumers, in turn the purchase intention. Moreover, poor service quality appears to have a negative influence on consumers' decision to transact online [56]. Therefore, the following hypothesis is proposed:

H5: Service quality has a positive influence on the mobile app ratings for mobile banking apps in India.

\subsubsection{Login Time}

Additionally, based on the pre study and in line with previous research, this study conceptualized new construct i.e., Login time. Login time refers to the time taken by a user to login to their respective mobile banking apps. Traditionally, a login requires either a username and password or a customer ID and password to login to an account. Nowadays, with enhanced security, additional layers of authentication have been added to the login system and as a result, the time to log-in to a particular mobile app varies as per the retail banks. For example, few banking apps require a username/customer ID followed by account image and a onetime password (OTP) to login to mobile banking whereas some of the banks only require customer ID's and password to login. Login Time as an attribute was identified through multiple focus group interviews with industry experts. Therefore, based on this qualitative research, we hypothesize that:

\section{H6: Login Time has a negative influence on the mobile app ratings for mobile banking apps in India.}

\section{Pre Study}

A pre study was conducted prior to the final survey rollout, to identify the attributes from a customer's point of view. The pre study was based on focus group study of mobile banking users in Delhi. Focus groups enable participants to talk about tacit knowledge and non-reflexive practices. By interacting with others, we shape and reshape our thoughts about things we do more or less consciously [28]. The detailed accounts and explanations given by the participants stimulate associations, which, in turn, produce a rich material [22]. This is particularly useful when studying the use of technology, for example, the mobile phones which are primarily a routine and unconscious action involving inferred knowledge. Finally, the focus group interview is also deemed appropriate in that it is a method capable of producing both breadth and depth of the collected empirical material in a short period of time [43]. Focus group material produces knowledge about actual activities; in this case, mobile banking activities [28]. The analysis presented below draws on material generated from five focus groups. The data collection was carried out during 2017 and 2018. Each focus group consisted of 5-7 participants: a total of 47 people (20 women and 27 men) between 25 and 35 years of age (Table 1). 
The participants were post graduate students and working professionals from Delhi, India and were recruited in two rounds. The first round generated two focus group interviews, of which nine participants were women and fifteen, were men (Table 1). In the second round, three group discussions were moderated with eleven females and twelve males. The participants were rewarded with food coupons. The profiles of the five group members is shown in Table 2.

Table 1: Focus interview and group discussions

\begin{tabular}{|l|l|l|l|l|}
\hline $\begin{array}{l}\text { Group } \\
\text { No. }\end{array}$ & Women & Men & Occupation & Age \\
\hline 1 & 4 & 7 & Working Professionals & $25-35$ \\
\hline 2 & 5 & 8 & Working Professionals & $25-35$ \\
\hline 3 & 4 & 3 & College students & $25-28$ \\
\hline 4 & 3 & 4 & Working Professionals & $18-25$ \\
\hline 5 & 4 & 5 & College students & $25-28$ \\
\hline Total & 20 & 27 & & \\
\hline
\end{tabular}

Table 2: Profile of focus group members

\begin{tabular}{|l|l|l|l|l|l|l|l|l|}
\hline $\begin{array}{l}\text { Group } \\
\text { No. }\end{array}$ & Women & Men & Occupation & Age & $\begin{array}{l}\text { Mobile } \\
\text { banking } \\
\text { exp }\end{array}$ & $\begin{array}{l}\text { Frequency of } \\
\text { use of } \\
\text { banking apps }\end{array}$ & $\begin{array}{l}\text { Number of } \\
\text { apps } \\
\text { installed } \\
\text { (On an } \\
\text { average) }\end{array}$ & $\begin{array}{l}\text { Frequency } \\
\text { of use of } \\
\text { apps, other } \\
\text { than } \\
\text { financial } \\
\text { apps }\end{array}$ \\
\hline 1 & 4 & 7 & $\begin{array}{l}\text { Working } \\
\text { Professionals }\end{array}$ & $25-35$ & $>2$ yrs & $\begin{array}{l}\text { Once in few } \\
\text { days }\end{array}$ & 13 & Almost daily \\
\hline 2 & 5 & 8 & $\begin{array}{l}\text { Working } \\
\text { Professionals }\end{array}$ & $25-35$ & $3-4$ yrs & Almost daily & 11 & Almost daily \\
\hline 3 & 4 & 3 & College students & $25-28$ & $1-2$ yrs & $\begin{array}{l}\text { Once in few } \\
\text { weeks }\end{array}$ & 15 & Almost daily \\
\hline 4 & 3 & 4 & $\begin{array}{l}\text { Working } \\
\text { Professionals }\end{array}$ & $18-25$ & $>2$ yrs & Almost daily & 17 & Almost daily \\
\hline 5 & 4 & 5 & College students & $25-28$ & $>3$ yrs & $\begin{array}{l}\text { Once in few } \\
\text { days }\end{array}$ & 23 & Almost daily \\
\hline Total & 20 & 27 & & & & & \\
\hline
\end{tabular}

Compliant with the aim of this paper, the interviews focused on how, when and why participants use mobile apps for financial transactions. A semi-structured interview guide was used to ensure consistency in the questions asked across the focus groups [43]. Initially, the participants were asked to freely describe and discuss the use of their smart phones for financial transactions. At different points, we raised specific questions like: HDFC What financial transactions do you carry out using your mobile apps?, What makes your mobile banking app usage, a seamless experience and What factors are important from the stand point of carrying out financial transactions using mobile apps?. The group sessions lasted between 45 and $60 \mathrm{~min}$, and were recorded and fully transcribed. The moderator took notes throughout the sessions and these were transcribed afterwards.

Data were analyzed in an iterative process, alternating between data collection and analysis, often recommended in research focusing on social activities [2]. The analysis was conducted in four different phases. In the first phase, a systematic examination of the transcripts to identify individual items was conducted. During the first phase of the analysis, we searched for individual items for mobile apps and coded the items. Forty eight items of mobile attributes were identified in this phase of the analysis. In the second phase, we searched themes for each of the items [52]. The forty eight items were categorized under seven broad themes. In the third phase, we identified different ways in which the participants discussed how mobile app attributes of a particular retail bank affected them. During the fourth phase, mobile attributes identified through literature were combined with the ones identified through the focus group discussion and tested through a pilot study. Finally, a total of 6 themes and 33 items were identified (Table 4). Out of the six themes, five themes were related to the constructs, identified from pre-validated research namely visual, navigational, information, collaboration designs and service quality. A new construct was proposed in the study, i.e. Login Time. A series of focus interviews were also conducted, as a part of the pre study with the industry experts. The industry exerts were typically people from a mid management level to senor management level working with leading public and private sector banks in India. Login Time came as a variable, which was common across all interviews. One of the senior executive, working with a private sector bank during the interview quoted Consumers now days prefer a higher login time for their mobile apps. They churn to other mobile apps, if they do not get a seamless experience with the mobile app. Login time, plays a crucial role here. Login time refers to the time taken by 
a user to login to their respective mobile banking apps. Based on the pre-validated items under each construct and the items identified in the pre-study, a pilot test of 71 graduate level college students who had banked online through mobile apps in the last two week was then conducted to further test the format and the wording of the instrument. In summary, the mobile app attributes, emerging from this research phase consisted of items clustered under six constructs, categorized as below:

1. Visual design ( 6 items, alpha=0.79).

2. Information design (7 items, alpha=0.87).

3. Navigational design (5 items, alpha=0.83).

4. Collaboration design (5 items, alpha=0.82).

5. Service quality (5 items, alpha $=0.88)$

6. Login time (5 items, alpha $=0.71)$

\section{Conceptual Model}

The conceptual model guiding our study is shown in Figure 1. The research model was developed based on conceptual and empirical studies in related disciplines. The model posits that visual, navigation; information; collaboration; service quality and login time related mobile app attributes influence a customer rating for a particular mobile banking app to a significant level.

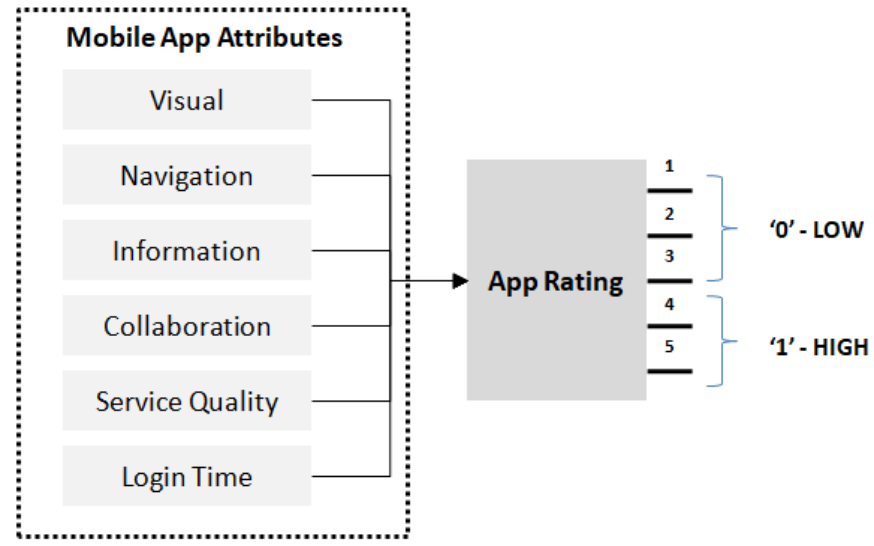

Figure 1: Research model

The mobile app attributes such as visual, information, navigational, collaboration and service quality design have been taken from existing literature, whereas login time has been identified through a series of personal interviews and focus group discussion with industry experts. Mobile app rating here is defined as a numeric number assigned to mobile banking apps for various retail banks in India on a scale of 5 . A rating of 1-3 is defined as a low rating whereas ratings between $4-5$ are defined as high. The reviews are not considered as part of the ratings as the study only focuses on the numerical value, which is given on a scale of 1 to 5 .

\section{Data and Methodology}

This section illustrates the sample, data collection method and instrument development along with assessing the measurement as well as the structural model.

\subsection{Data Collection and Sample}

Our study employed a survey of smart phone users to gather data for hypotheses testing and to address research objectives. Before conducting the survey, we first considered the sample size. Earlier work [54], [55], suggested that the sample size for social science research should be greater than 15 times the number of predictors. There are 6 predictors in our model and the sample size should therefore be larger than 90. An invitation email with a link to the survey site was sent to 914 college students. In the beginning of the survey, respondents were asked whether they currently use mobile banking apps for their financial transactions. Respondents with a No were excluded from the 
study. We finally included 612 respondents for the survey. By excluding the nonusers, it ensured that all the remaining respondents were mobile banking users who had purchased food through mobile apps. The data collection lasted three weeks, beginning from February 2018.

A total of 396 responses were collected, which yielded a response rate of $55 \%$. Each questionnaire was scrutinized and eliminated if it had too many missing values. There were a total of 53 incomplete responses, 32 respondents had only filled in the profile details and did not attempt the questionnaire whereas the remaining respondents $(n=21)$ had answered only initial few questions and left the survey midway. As a result, 53 questionnaires were eliminated from the survey and finally, we obtained 343 valid responses (Table 3), which fulfilled the requirements of sample size mentioned above. Among them, $47 \%$ were female and $53 \%$ were male. A majority of respondents were aged between 23 and 32 years (69\%). More than half (64\%) held a bachelor's degree. Around $88 \%$ of the respondents had savings account with four retail banks in India (HDFC, ICICI, Axis and $\mathrm{SBI}$ ) and $68 \%$ of the respondents had transacted using mobile apps in the last one month. The most commonly used mobile banking app was of HDFC Bank, State Bank of India (SBI, ICICl Bank and Axis Bank. Millennial were chosen as the sample for the study for four main reasons (1) The average age of mobile banking users in India, around 26- 30 years (2) Total mobile app downloads for banking institutes in India is highest for Millennial and (3) the total volume of transactions across the major mobile banking applications in India is the maximum for Millennial. Therefore, the propensity of Millennial toward mobile banking is more than any other consumer segment, thus we have taken Millennial as the sample for our study. More details about the demographics of the sample and banking behavior are presented in Table 1.

\subsection{Instrument Development}

Items to measure the focal constructs of the study were drawn from pre-validated research (Appendix A) and were modified based on the pre study to suit the specific context of the study. Specially, items of visual design were adapted from [34], [44]. Items of visual design reflect the visual appeal, size and color of fonts and aesthetics. Items of information design were adapted from [47] and captured menu options, content, account details, financial transactions and investment options. Navigational design items were taken from the study of [10]. It reflects the navigation bar and links to other pages etc. Items of service quality were taken from Clemes (2013), which relates to customer's perception of the result of the service and service recovery [15]. Items of collaboration design were adapted from Kapoor and Vij (2018), which measures the scale of alliances with other players in the industry. In the case of mobile banking, service options such as online cheque book request, connect with an advisor option, chatbots, call me option and online requests are some of the parameters for service quality. In [51], e-service quality as consumers overall evaluations and judgments of the quality of e-service provided by online companies.

Table 3: Demographic characteristics of respondents $(\mathrm{N}=343)$

\begin{tabular}{|l|l|l|l|}
\hline Demographics & Category & Frequency & $\%$ \\
\hline Gender & Male & 181 & $53 \%$ \\
\hline & Female & 162 & $47 \%$ \\
\hline Age (Yrs) & $18-21$ & 62 & $18 \%$ \\
\hline & $22-25$ & 113 & $33 \%$ \\
\hline & $26-29$ & 124 & $36 \%$ \\
\hline & $>29$ & 44 & $13 \%$ \\
\hline Education & Graduate & 112 & $33 \%$ \\
\hline & Post Graduate & 218 & $64 \%$ \\
\hline Occupation & PhD or above & 13 & $4 \%$ \\
\hline $\begin{array}{l}\text { Mobile banking } \\
\text { experience }\end{array}$ & College Students & 343 & $100 \%$ \\
\hline & $<1$ year & 31 & $9 \%$ \\
\hline & $1-2$ years & 74 & $22 \%$ \\
\hline & $2-3$ years & 67 & $20 \%$ \\
\hline $\begin{array}{l}\text { Mobile apps } \\
\text { used (Banking) }\end{array}$ & $>3$ years & 171 & $50 \%$ \\
\hline & HDFC Bank & 93 & $27 \%$ \\
\hline & SBI State Bank of India) & 82 & $24 \%$ \\
\hline & ICICl Bank & 75 & $22 \%$ \\
\hline & Axis Bank & 53 & $15 \%$ \\
\hline $\begin{array}{l}\text { Frequency of } \\
\text { usage }\end{array}$ & Others & 40 & $12 \%$ \\
\hline & Once a week & 119 & $35 \%$ \\
\hline & Once in few weeks & 113 & $33 \%$ \\
\hline & Once a month & 88 & $26 \%$ \\
\hline Level of usage & Static in few months & 23 & $74 \%$ \\
\hline & Dynamic & 151 & $52 \%$ \\
\hline
\end{tabular}




\subsection{Data analysis Technique}

After the data were collected and tabulated, a series of statistical assumptions were tested to ensure the appropriateness of the data for factor analysis. The results show that the most of the correlation matrices were greater than 0.04 , and the anti- image correlation matrix illustrates that the majority of these values are close to zero. Bartlett's test of sphericity was high (7414.860) and the level of significance was low $(0.0000)$. Moreover, the KaiserMeyer-Olkin value was 0.814. In [14], [31], the value is meritorious, which implies that the variables belong together and are appropriate for factor analysis [14]. As a result, the data was deemed appropriate for factor analysis.

A factor loading of +-0.05 was used as a guideline to identify significant factor loadings as +-0.05 produced a clearer structure and increased the robustness of the factor rotation [17]. In the present study, the results of the latent root criterion demonstrated that the 33 variables submitted for factor analysis were extracted to form six dimensions. These six dimensions explained $83.43 \%$ of the variation in the data. The six dimensions are (1) visual design, (2) navigational design, (3) information design, (4) collaboration design and (5) service quality and (6) login time.

\subsubsection{Measurement Model}

The assessment of the reliability and validity constructs was done as per the recommendation made in [23], [26]. The collected data were processed and analyzed by statistical software package SPSS 23.0 and AMOS 18. The items used to measure each factor were tested for reliability by using Cronbach's alpha value of 0.70 as the cut-off point for exploratory research as suggested in [13]. In this study, all of the factors have a Cronbach's alpha values greater than 0.70. Next, the uni-dimensionality of each construct was assessed using confirmatory factor analysis (CFA). The fit measures considered in the study were: goodness of fit index (GFI), adjusted goodness of fit index (AGFI), Tucker-Lewis index (TLI), incremental fit index (IFI), and comparative fit index (CFI). As shown in Table 4, all the model-fit indices exceeded the respective common acceptance levels suggested by previous research, demonstrating that the measurement model exhibited a good fit with the data collected.

Table 4: Fit indices for measurement and structural model.

\begin{tabular}{|l|l|l|l|}
\hline Fit Indices & Recommended value & Measurement model & Structural model \\
\hline $\mathrm{X} 2 / \mathrm{df}$ & $\leq 3.00$ & 2.09 & 2.01 \\
\hline $\mathrm{CFI}$ & $\geq 0.90$ & 0.956 & 0.947 \\
\hline $\mathrm{GFI}$ & $\geq 0.90$ & 0.934 & 0.933 \\
\hline $\mathrm{AGFI}$ & $\geq 0.80$ & 0.928 & 0.927 \\
\hline $\mathrm{IFI}$ & $\geq 0.90$ & 0.949 & 0.938 \\
\hline $\mathrm{TLI}$ & $\geq 0.90$ & 0.939 & 0.931 \\
\hline RMSEA & $\leq 0.08$ & 0.048 & 0.044 \\
\hline
\end{tabular}

Furthermore, another key reliability measures namely composite reliability (CR) and average variance extracted (AVE) were also computed for all constructs to assess their internal consistency. The values of composite reliability (CR) for all constructs were greater than 0.845 signifying that the proposed research model has reasonably good internal consistency. In addition to it, the average variance extracted (AVE) and composite reliability (CR) confirmed the convergent validity of all the constructs, as the values of CR are greater than AVE.

To examine discriminant validity, we followed the method suggested in [22], [23]. We compared the square root of the AVE of each construct and its correlation coefficients with other constructs. The results in Table 5 showed that the square roots of the AVEs were larger than the corresponding correlation coefficients, thus showing sufficient discriminant validity. In summary, the measurement model demonstrated adequate reliability, convergent validity, and discriminant validity.

Table 5: Discriminant validity of measurement model

\begin{tabular}{|c|c|c|c|c|c|c|c|c|}
\hline & CR & AVE & VIS & INF & NAV & COLL & SER & LT \\
\hline VIS & 0.785 & 0.665 & $\mathbf{0 . 8 1 5}$ & & & & & \\
\hline INF & 0.912 & 0.881 & 0.565 & $\mathbf{0 . 9 3 8}$ & & & & \\
\hline NAV & 0.905 & 0.876 & 0.381 & 0.465 & $\mathbf{0 . 9 3 5}$ & & & \\
\hline COLL & 0.862 & 0.812 & 0.432 & 0.378 & 0.334 & $\mathbf{0 . 9 0 1}$ & & \\
\hline SER & 0.808 & 0.786 & 0.436 & 0.564 & 0.424 & 0.675 & $\mathbf{0 . 8 8 7}$ & \\
\hline LT & 0.791 & 0.731 & 0.312 & 0.424 & 0.526 & 0.645 & 0.634 & $\mathbf{0 . 8 5 4}$ \\
\hline
\end{tabular}

Diagonal elements are square root of AVE, others are correlation coefficients.

To examine the potential common method bias, we performed two statistical analyses to assess the severity of common method bias. First, a Harman's single-factor test suggested in [46] was conducted on the four constructs. We found that no single-factor emerged and the first factor accounted for $31.4 \%$ of the $78.3 \%$ explained variance. Second, the study conducted a CFA to assess the fit of a single-factor model (all items loading on one factor). The 
single-factor model showed a very poor fit $(\mathrm{X} 2 / \mathrm{df}=12.48, \mathrm{CFI}=0.689, \mathrm{GFI}=0.612, \mathrm{AGFI}=0.55, \mathrm{NFI}=0.618, \mathrm{TLI}=0.488$, RMSEA $=0.312$ ). Both tests confirmed the absence of common method bias.

\subsubsection{Structural Model}

A similar set of fit indices was used to examine the structural model. Comparison of all fit indices, with their corresponding recommended values, provided evidence of a good model fit $(X 2 / \mathrm{df}=2.01, \mathrm{CFI}=0.947, \mathrm{GFI}=0.933$, $A G F I=0.827, \mathrm{IFI}=0.938, \mathrm{TLI}=0.931, \mathrm{RMSEA}=0.044$ ). Thus, we could proceed to examine the path coefficients of the structural model.

Moreover, we checked multicollinearity by calculating the variance inflation factor (VIF). The resulting VIF values of all the regressions were all substantially below the cut-off values of 10 (the maximum value is 6.86), indicating no serious problems of multicollinearity. The testing of hypothesis was conducted using beta values for hypothesized paths at $5 \%$ level of significance. The results in Fig. 2 show that all the hypotheses $\mathrm{H} 1, \mathrm{H} 2, \mathrm{H} 3, \mathrm{H} 4, \mathrm{H} 5$ and $\mathrm{H} 6$ are well supported. All the paths proposed are significant, with a $p$-value of less than 0.05 .Information design positively affected app rating $(\beta=0.68, p<0.01)$, confirming $\mathrm{H} 1$ and explain a significant amount $(78.8 \%)$ of variation in app ratings. Navigation design has a significant positive effect on app rating $(\beta=0.57, p<0.01, \mathrm{H} 2$ supported). Collaboration design is positively associated with app rating $(\beta=0.36, p<0.01, \mathrm{H} 3$ supported) followed by Service design ( $\beta=0.27, p<0.01, \mathrm{H} 5$ supported) and visual design $(\beta=0.17, \mathrm{p}<0.01), \mathrm{H} 6$ supported). Although the impact of visual design is positive, it had the least effect on app rating. Login-time had a significant negative effect on app rating ( $\beta=-0.48, p<0.01, \mathrm{H} 4$ supported). Further, the explained variance of navigation design, collaboration design, login-time, service design and visual design was $72.4 \%, 61.3 \%, 54.8 \%$ and $44.2 \%$, and $17.8 \%$ respectively.

\subsubsection{Multivariate Analysis}

Followed by factor analysis, a logit model was used in this study to analyse Indian consumer's mobile banking decision due to the binary nature of the dependent variables. Logistic regression analysis is the most popular technique available for modeling dichotomous dependent variables [25], [27]. The literature on using logistic regression analysis for mobile banking behavior is sparse. However, there is an increasing trend in using logistic regression analysis in economic and behavioral research because of existence of many discrete variables. For example, in [5], it advises that the logistic regression is not only applicable to college enrollment, but also to behaviors such as college persistence, transfer decisions, and degree attainment. Moreover, in [14] a logit analysis is used to analyze the factors that contribute to bank switching behavior in New Zealand and China, respectively.

The dependent variable in our study, the rating for mobile banking app, is dichotomous. Therefore, the logit model is: $\mathrm{P}($ High app rating $)=\pi(x)=\frac{e^{g(x)}}{1+e^{g(x)}}$

and thus

$\mathrm{P}($ Low app rating $)=1-\pi(x)=\frac{1}{1+e^{g(x)}}$

Where $\mathrm{g}(\mathrm{x})$ represents the independent: login time, visual design, navigation design, information design, and collaboration design and service levels.

Consumers' ratings for mobile banking apps are hypothesized to be affected by the following factors and can be implicitly written under the general form:

APPrating $=f(L T, V D, N D, I D, C D, S L$, error $)$

The discrete dependent variable, APPrating, measures the rating provided by users for their mobile banking apps. The dependent variable is based on the question asked in the mail intercept survey: How do you rate your mobile banking app? APPrating take a value of 1 if the respondent rates it above 3 and 0 otherwise. In the equation, LT is login time, VD is visual design, ND is navigation design, ID is information design, CD is collaboration, SL is service level and error is an error term.

\section{Results and Findings}

The items used to measure each factor were tested for reliability by using Cronbach's alpha value of 0.70 as the cutoff point for exploratory research as suggested in [13]. In the present study, all of the factors have a Cronbach's alpha values greater than 0.70 .

Logistic regression analysis was used to identify the factors that influence Indian consumer's decisions to rate a particular mobile banking app (see Table 6). In general, the model fitted the data very well (Chi-square $=512.76367$, $P$ value $=0.0001$, Degree of Freedom $(\mathrm{df})=22$ ). The model explains $83.43 \%$ of the variance in the rating provided for mobile banking apps. The result for the significant decision factors are shown in Table 2. 
The coefficient values for information design, navigation design and collaboration are significant at the 0.01 level of significance. Visual design, login time and service quality are significant at 0.05 level of significance. The results in Table 6 show that visual design, navigation design, information design, collaboration and service level have positive influences on Indian consumers' decision to rate a mobile banking app, providing support for hypothesis $\mathrm{H} 1, \mathrm{H} 2, \mathrm{H} 3$, $\mathrm{H} 4, \mathrm{H} 5$ and $\mathrm{H} 6$. The results also show that login time significantly influence Indian consumers' ratings for mobile banking apps negatively. Thus hypothesis $\mathrm{H} 6$ is supported.

Table 6: Logistic regression results (influencing factors on rating for mobile banking apps)

\begin{tabular}{|l|l|l|l|l|}
\hline Number of observations: & & 343 & & \\
\hline Log Likelihood function: & & -83.14668 & & \\
\hline Restricted log likelihood: & & -380.34164 & & \\
\hline Chi-squared statistics: & & 497.64667 & & \\
\hline Degree of freedom: & & 22 & & \\
\hline Prob (ChiSqd>value): & & 0.00001 & & \\
\hline McFadden R2: & & 0.8365108 & & Marginal effects \\
\hline & Coefficients & Std error & Sig. & 0.5686 \\
\hline Information design & 3.12825 & 0.26126 & $0.0001^{* *}$ & 0.2861 \\
\hline Navigation design & 2.41578 & 0.21638 & $0.0000^{* * *}$ & 0.3084 \\
\hline Collaboration & 2.07976 & 0.18611 & $0.0004^{* * *}$ & -0.2937 \\
\hline Login time & -1.51674 & 0.19976 & $0.0196^{* *}$ & 0.4488 \\
\hline Service quality & 1.38713 & 0.23023 & $0.0228^{* *}$ & 0.1535 \\
\hline Visual design & 0.65483 & 0.27818 & $0.0173^{* *}$ & \\
\hline
\end{tabular}

"Statistically significant at $\mathrm{p}<0.05$ level of significance

"'." Denote statistically significant at $p<0.01$ level of significance

Table 7: Marginal effects of the decision factors.

\begin{tabular}{|l|l|l|}
\hline Factors & Marginal effect & Ranking \\
\hline Information design & 0.5686 & 1 \\
\hline Navigation design & 0.2861 & 5 \\
\hline Collaboration & 0.3084 & 3 \\
\hline Login time & -0.2937 & 4 \\
\hline Service quality & 0.4488 & 2 \\
\hline Visual design & 0.1535 & 6 \\
\hline
\end{tabular}

Furthermore, marginal effect analysis was used to rank the six decision factors that have impact on consumers' rating for mobile banking apps, from the most important to least important. The marginal effects shown in Table 5 are calculated as the partial derivatives of the non-linear probability function evaluation at each variable's sample mean [38], [48]. The marginal effect also determines the marginal change in the dependent variable, holding other variables constant [38]

According to the results of marginal effect analysis in Table 7, information design has the maximum impact on consumers' rating for mobile banking apps. For example, a unit increase in the navigation design factor results in an estimated $56.86 \%$ increase in the probability of consumers rating the mobile app as high. Similarly, a unit increase in service quality results in $44.88 \%$ probability of a consumer rating a mobile banking app as high. Collaboration was ranked as the third most important decision factor followed by login time as the fourth decision factor, navigation was the fifth most important factor and lastly visual design was the least important factor while rating a particular mobile banking app.

\section{Discussion, Conclusion and Implications}

With the increasing popularity of mobile apps, marketing scholars and practitioners have recognized that mobile apps are effective digital communication and consumer engagement tools [33]. To explore the role of mobile app in consumer engagement, the current study developed and empirically tested a model to examine the decision factors for rating mobile banking apps and subsequently to determine the order of importance of the factors that has impact 
on user's ratings for mobile banking apps in India. Specifically, we provided empirical evidence that visual, navigational, information, collaboration, service quality and login time has a significant effect on app rating.

The research also offers some valuable insights into the linkage between mobile app ratings and mobile app attributes for retail banking and the attributes consumers prefer while using mobile banking. This information can help retail banks to develop appropriate design strategies for their mobile interface and make the correct marketing decisions in order to retain their current customers and attract new customers.

This study indicates that information design has the strongest influence on the ratings of customers for mobile banking apps. This relation is consistent with other studies [37], [44], [60], who asserted that information quality positively influences a customer's purchase decision. Consumer expects accurate up-to date and comprehensive information on the mobile app. In case of mobile app for retail banks, information such as account statement, investment decisions, payment history, historic statements and portfolio monitoring etc are part of the information design. Customers prefer all relevant information under one roof i.e. mobile app. Thus, retail banks in India need to invest in providing relevant yet easy to understand information. The mobile app should be able to prompt users with real time information, in order to meet customers' rocketing expectation set by other industries.

The result of this study revealed that service quality had the second most influence on user ratings. It influences users' decision to transact online to a great extent. This result is consistent with a number of researchers regarding service quality as a priority and one of the primary concerns in e-commerce [6], [51], [59]. In an online banking context, the neglect of consumers' concerns and inquiries lead to customer dissatisfaction. Hence, retail banks need to offer a prompt and responsive query management system to customers' concerns, complaints and inquiries. For example, along with using communication channels such as e-mail or phone banking assistant, retail banks can also offer live customer support, similar to airlines or any of the e-commerce companies providing a more personalized service. Another aspect of service quality that retail banks should not overlook is the personalized online banking environment. Earlier work [59], claim that consumer loyalty and their online experience can be improved using a personalized, online banking environment. Hence, retail banks need to develop online marketing strategies to personalize banking environment in order to meet different consumers' needs and preferences. For example, in case of payment at multiple outlets such as restaurants or super markets, an easy to use scan-pay-order process could really speed up the transaction for a user and eventually enhance the service quality.

We found that in addition to information and service quality, collaboration design also significantly affects user ratings. Collaboration design refers to alliances between the retail banks and other e-commerce players in order to provide discounts or cash back. The positive relationship between collaboration and user satisfaction is consistent with the findings in [46], which asserted that consumers are driven by offers and discounts, provided by online retailers. Most of the retail banks have tied up with e-commerce players like Amazon, food aggregators like Zomato, cab service providers like Uber and many more. As a result of such collaboration, retail banks, allows consumers to avail a cash back or discount, making them transact using their respective mobile apps. Consumers always expect to save while shopping and college students especially do so since they depend largely on pocket money from their parents. An extra discount on the final purchase value is always appreciated. For example, HDFC bank mobile app in India, PayZapp has a tie up with cab service provider Uber, wherein a user gets $10 \%$ cash back, whenever he/she uses Uber and makes a payment via PayZapp. Similarly, a user gets $25 \%$ cash back, whenever grocery is ordered online, through online retailer (Site 4). In [46], it was argued that a customer's propensity to choose a particular online retailer largely depends on the cash back being provided by the retailer. On the other hand, if no cash back or discounts are provided, consumers tend to use mobile apps of other players in the market. The working of mobile apps is fundamentally the same across retail banks in India, since mobile apps are primarily used for accessing account information and financial transactions. Therefore, alliances with other e-commerce players, resulting in discounts or cash backs becomes an important and determining element under collaboration design for customers. There are multiple retail banks that also have alliances with e-commerce players and offers discounts on using their mobile apps. However, a customer will only be influenced by a retail bank, if the discount being offered is on the product/service used/purchased by a consumer. For example, if a customer watches movie frequently, he/she would want to have offers on online ticket platform (Site 3). The customer would prefer to use mobile banking apps of retail banks, which offer discounts/cash back on Site 3. Therefore, it is important for online aggregators to understand the preferences of their customer base and create alliances with players, which are preferred by their customer base.

The results of this study also indicate that Login Time has a negative influence on user ratings. Higher the login time, lower the app ratings. Thus, retail banks should ensure that the login mechanism should be a smooth and prompt process. The findings suggest that consumers prefer to have mechanism in which, login to a mobile banking app is easy and less time consuming. Traditionally, a login requires either a username and password or a customer ID and password to login to an account. Nowadays, with enhanced security, additional layers of authentication have been added to the login system and as a result, the time to log-in to a particular mobile app varies as per the retail banks. For example, few banking apps require a username/customer ID followed by account image and a onetime password (OTP) to login to mobile banking whereas some of the banks only require customer ID's and password to login. Point worth discussion is whether enhanced securities counter balances a higher login time. Security is of paramount importance in financial applications. All banks have security measures in place in order to make mobile banking a safe experience for its users. Banks add additional layers of security such as two level and in some cases even a three level user authentication, before a user login to a particular mobile banking app. Respondents in the 
study identified login time as an important factor for rating a particular mobile app. Respondents had given a lower rating to mobile apps with higher login time as compared to apps with a lower login time. If users are given a choice to choose between higher security vis-à-vis a lower login time, perhaps higher security would supersede lower login time. However, in order to give a seamless experience to the user, a higher login time can also not be ignored since it was identified that higher login time is a pain area for users.

If we compare the authentication process of Apple $X$ series using face recognition, it takes seconds to authenticate a particular user and provided him/her with user access. The algorithm used behind apple's face recognition software is complex yet safe and time saving. It is a secured way of authentication and yet less time consuming. The idea is whether there exists a possibility, where systems can be designed wherein users login to their mobile banking apps in no time and yet does not compromise on the security aspect. Most of the Indian banks have a two level authentication process ensuring that security standards for these banks follow a specific standard. Therefore, a user would expect similar login time for banks with similar authentication process. It is of paramount importance for banks in India to come up with game changing design features such as face or voice recognition, which takes seconds to authenticate and identify a consumer and enables a consumer to login to his/her account in no time without compromising the security and privacy.

In terms of Navigation in a mobile app, it significantly influenced the user ratings as well. Navigational design refers to the transition for a customer from one page to another. For example, if user has to transfer an amount to a beneficiary, how easy it is to select the beneficiary, proceed with verification and transferring the money. Some banking apps enables you to select a beneficiary by providing details of the beneficiary and with the help of a OTP, the beneficiary is added and the amount is transferred whereas in some cases, you have to provide a profile password, even after login and then an OTP is received, in order to transfer the amount. A seamless transition between multiple pages is preferred by customers and influences their purchase decision to a great extent. The argument is supported in [59], which states that links to other web pages and seamless navigation experience improves customers experience and results in conversion. Effective navigation enables customers to transact quickly and make online payments in no time and enables a seamless payment experience as well.

Our study revealed that visual design also has a positive effect on user rating. Though visual design has the least effect on user rating, but the aesthetics are always important while designing a mobile app. Variables that are significant predictors of app ratings include fonts and color combinations used by the provider. Icons, images and pictures are associated with a higher rating. Results for the visual attributes indicate that visual designs that incorporate interactivity increase the appeal of internet sites [26]. Customers prefer mobile apps of retail banks with pleasant color combinations, handpicked icon used and images of individuals, they can relate to. The color combination used along with the font sizes also plays a very vital role in choosing a particular retail bank mobile app. This study makes several important contributions to research. First, to our knowledge, this study is one of the very few that has attempted to investigate the relationship between mobile app attributes and user ratings for retail banks. As noted earlier, extant research has focused on consumers' initial adoption and acceptance of mobile apps, and has seldom considered mobile app attributes, which is critical to a retail banks' success. In this regard, our study contributes to existing literature by providing new insights into mobile app attributes of retail banks and their effects on user ratings. Second, with the help of a series of focus group discussion with the users of mobile apps, a new dimension of login time was identified. Login Time is a construct which has evolved with technology and FinTech startups in India.

Third, prior studies on mobile app attributes largely ignored the operational aspects of mobile apps and focused more on the adoption levels. Previous research has mainly adopted Technology Acceptance Model (TAM) and Unified Theory Use of Technology (UTAUT) as a theoretical basis and investigated the roles of instrumental beliefs such as perceived usefulness and performance expectancy in determining mobile app attributes. However, mobile user is not only affected by perceived usefulness and performance expectancy which are extrinsic motivations, but also by mobile attributes, which is an intrinsic motivation. Lastly, the study measures the effect of mobile app attributes on user ratings. Prior studies have identified the effect of app attributes on using a particular mobile app, whereas present study identifies the effect of app attributes on actual user ratings.

From a managerial point of view, this study offers salient insights for retail banks and marketers regarding the retaining of existing users and facilitation of higher satisfaction and new user sign ups. Earlier, a user could only login to an account, where he/she had a savings or a current bank account. Nowadays, a user can login to mobile app of any bank, irrespective of whether the user has an account with the bank or not. With the emergence of cardless payment options, mobile wallets and e-wallets, a user can download a mobile app of any retail bank through the app stores and log-in to transact online. Although many of the practical implications have been discussed earlier in this section, our results highlight that retail banks need to take the functional characteristics of their mobile apps (e.g. visual, navigation, information, login time, service quality and collaboration) design, into consideration when encouraging users' continuance intention towards online transactions. Regarding information design, retail banks need to have an accurate and up -to- date information about products/services and digital touch points such as chat bots. The mobile app should offer a seamless navigation experience to the user. The service quality of a banking app needs to provide an Omni channel banking experience. For example, enabling customers to withdraw money at an ATM directly from their mobile app and allowing customers to complete a transaction without any further credentials or hassle. Regarding collaboration design, retail banks need to have relevant alliances with ecommerce 
players to offer discounts and cash back options for their users and improved app ratings. Dynamic filter options and multiple payment modes are preferred by customers, which retail banks should be cognizant of, while designing their mobile app. The color combination used along with the font sizes also plays a very vital role in choosing a particular service provider. Image quality help to develop immediate interactivity with the customer. It was brought out during the focus group discussion that customer have churned from one retail banking app to other, since the apps were not integrated well with e-wallets of e-commerce players such as Paytm etc in India. Therefore, retail banks need to focus on the navigation capabilities of their mobile app and need to make sure that they are integrated with all major payment gateways and e-wallets. The time taken to login to a mobile app is also a crucial attribute and influences the behavior of consumers to a great extent. Mobile apps with relatively less complex login procedure were preferred by users over the ones, with complex and time consuming login procedure. Therefore, visual, navigational, information, collaboration designs, service quality and login time are the key attributes which need to be factored in, while designing an effective mobile strategy and developing a user friendly mobile banking app.

\section{Limitations and Avenue for Future Research}

Although this study has provided relevant and interesting insights to the understanding of consumers' user rating towards mobile banking apps in India, there are limitations associated with the research. The study has been conducted with methodological rigor, although the findings should be interpreted with caution. First, we conducted this research in India, where mobile commerce is developing rapidly but is still in its early stage. Thus, our results can only be generalized to other countries that have a developing mobile commerce market. Future research might focus on online shopping behavior of consumers using mobile apps of specific banks (e.g., online marketplaces shopped at, product categories, mode of preferred payments etc). The information obtained may offer additional and useful information to marketers, online retailers and retail banks.

Second, in addition to the six decision factors that impact on consumers' rating for mobile apps in this study, there may be other factors that may affect consumers' rating behavior. Financial applications are particularly sensitive to security issues and variables such as trust, security and privacy cannot be ignored while studying mobile banking apps. It would be interesting to see how variables such as safety, trust and privacy would influence the ratings of the mobile apps. Will security and privacy feature dominate over the design features? Future research should investigate other factors that may influence consumers' rating for mobile apps, such as product and service characteristics, trust and security issues. Third, the sample for this study was drawn from Delhi, India. The likelihood of online banking and the profile of consumers may vary if a survey is expanded to other geographic regions of India. Therefore, future studies needs to be conducted from different cities or different countries. This approach would allow for greater generalization of the results.

\section{Acknowledgements}

We are truly grateful to Faculty of Management Studies, University of Delhi, India for providing us with a promoting environment to carry out our research. We are also grateful and acknowledge the support from Indian Council of Social Science Research (ICSSR), Delhi to APK for carrying out the research.

\section{Website List}

Site 1: Amazon India

http://www.amazon.in

Site 2: Snapdeal

http://www.snapdeal.com

Site 3: Bookmyshow

http://www.bookmyshow.com

Site 4: Big Basket

http://bigbasket.com

\section{References}

[1] App Annie. (2018, July) App market data. AppAnnie. [Online]. Available: https://www.appannie.com/en/insights/

[2] S. Bellman, R. Potter, S. Treleaven-Hassard, J. Robinson, and D. Varan, The effectiveness of branded mobile phone apps, Journal of Interactive Marketing, vol. 25, no. 4, pp. 191-200, 2011.

[3] BCG. (2017, June) Encashing on digital: Financial services in 2020. BCG. [Online]. Available: http://imagesrc.bcg.com/Images/BCG-Facebook-Encashing-on-digital-Jun-2017 tcm21-163357.pdf 
[4] J. Boase and R. Ling, Measuring mobile phone use: Self- report versus log data, Journal of Computed Mediated Communication, vol. 18, no. 4, pp. 508-519, 2013.

[5] A.F. Cabrera, Logistic regression analysis in higher education: An applied perspective, in Higher Education: Handbook of Theory and Research (C Smart, Ed.). USA: Springer, 1994, pp. 225-256.

[6] S. Cai and M. Jun, Internet users' perceptions of online service quality: A comparison of online buyers and information searchers, Managing Service Quality, vol. 13, no. 6, p. 504, 2003.

[7] B.J. Calder and E.C. Malthouse, Media engagement and advertising effectiveness, in Kellogg on Advertising and Media (B. J. Calder, Ed.). Hoboken, NJ: Wiley, 2008, pp. 1-36.

[8] M. Castelli, L. Manzoni, L. Vanneschi, and A. Popovi, An expert system for extracting knowledge from customers' reviews: The case of amazon.com, inc., Expert Systems with Applications, vol. 84, pp. 117-126, 2017.

[9] R. Centeno, V. Fresno and J. Chaquet, From textual reviews to Individual reputation rankings: Leaving ratings aside solving MPC task, Expert Systems with Applications, vol. 114, pp. 1-14, 2018.

[10] I.C. Chang, P.C. Chou, R. Yeh, and H.T. Tseng, Factors influencing Chinese tourists' intentions to use the Taiwan medical travel app, Telematics and Informatics, vol. 33, no. 2, pp. 401-409, 2016.

[11] C. Cheung, X. Shen, Z. Lee, and T. Chan, Promoting sales of online games through customer engagement, Electronic Commerce Research and Applications, vol. 14, no. 4, pp. 241-250, 2015.

[12] C.J. Chou and C. Conley, Engaging experience: A new perspective of user experience with physical products, in Human Centered Design. HCD 2009. Lecture Notes in Computer Science, vol. 5619 (M. Kurosu, Ed.). Berlin, Heidelberg: Springer, 2009, pp. 31-40.

[13] G.A. Churchill, A paradigm for developing better measures of marketing constructs, Journal of Marketing Research, vol. 16, no. 1, pp. 64-73, 1979.

[14] M.D. Clemes, C. Gan and J. Zhang, An empirical analysis of online shopping adoption in Beijing, China, Journal of Retailing and Consumer Services, vol. 21, pp. 364-375, 2013.

[15] J.E. Collier and C.C. Bienstock, Measuring service quality in E-retailing, Journal of Service Research: JSR, vol. 8, no. 3, p. 260, 2006

[16] G. Cui, H.K. Lui and X. Guo, The effect of online consumer reviews on new product sales, International Journal of Electronic Commerce, vol. 17, no. 1, pp. 39-58, 2012.

[17] D. Cyr, M. Head and A. Ivanov, Design aesthetics leading to m-loyalty in mobile commerce, Informarion and Management, vol. 43, no. 8, pp. 950-963, 2006.

[18] F. Davis, Perceived usefulness, perceived ease of use, and user acceptance of information technology, MIS Quarterly vol. 13, no. 3, pp. 319-340, 1989.

[19] H.A. Dmour, M. Alshurideh and F. Shishan, The influence of mobile application quality and attributes on the continuance intention of mobile shopping, Life Science Journal, vol. 11, no. 10, pp. 172-181, 2014.

[20] Emarketer. (2016, November) Global mobile landscape: A country-by-country look at mobile phone and smartphone usage 2016. Emarketer. [Online]. Available: https://www.emarketer.com/Report/Global-MobileLandscape-2016-Country-by-Country-Look-Mobile-Phone-Smartphone-Usage/2001859

[21] H. Fang, J. Zhang, Y. Bao, and Q. Zhu, Towards effective online review systems in the Chinese context: A cross-cultural empirical study, Electronic Commerce Research and Applications, vol. 12, pp. 208-220, 2013.

[22] A. Fontana and J. Frey, Interviewing the art of science, Handbook Of Qualitative Research, vol 4, no. 7, pp. 361-376, 1992

[23] C. Fornell and D.F. Larcker, Evaluating structural equation models with unobservable variables and measurement error, Journal of Marketing Research, vol. 18, no. 1, pp. 39-50, 1981

[24] G. Ganu, N. Elhadad and A. Marian, Beyond the stars: Improving rating predictions using review text content, in Proceedings of the 12th international workshop on the web and databases, Rhode Island, 2009, pp. 1-6.

[25] G.D. Garson. (2010, July) Logistic regression. Faculty. [Online]. Available: http://faculty.chass.ncsu.edu/ garson/PA765/logistic.htm\#assume

[26] S. Ghose and W. Dou, Interactive functions and their impact on the appeal of internet presence sites, Journal of Advanced Research, vol. 38, no. 2, pp. 29-43, 1998.

[27] J.F. Hair, W.C Black, B.J. Babin, R.E. Anderson, and R.L. Tatham, Multivariate Data Analysis. New Jersey: Prentice Hall, 2006.

[28] B. Halkier, Focus groups as social enactments: Integrating interaction and content in the analysis of focus group data, Quality Research, vol. 10, no. 1, pp. 71-89, 2010.

[29] T. Hennig-Thurau, K.P Gwinner, G. Walsh, G and D.D. Gremler, Electronic word-of-mouth via consumeropinion platforms: What motivates consumers to articulate themselves on the internet? Journal of Interactive Marketing, vol. 18, pp. 38-52, 2004.

[30] Y. Ji, J. Park, C. Lee and M. Yun, A usability checklist for the usability evaluation of mobile phone user, International Journal of Human-Computer Interaction, vol. 20, no. 3, pp. 207-231, 2016.

[31] H.R. Kaiser and J. Rice, Little jiffy mark IV, Educational and Psychological Measurement, vol. 34, no. 1, pp. $111-117,1974$

[32] H. Kang, M.J. Lee and J.K. Lee, Are you still with us? A study of the post- adoption determinants of sustained use of mobile-banking services, Journal of Organizational Computing and Electronic Commerce, vol. 22, no. 2, pp. 32-159, 2012.

[33] A.P. Kapoor and M. Vij, Technology at the dinner table: Ordering food online through mobile apps, Journal of Retailing and Consumer Services, vol. 43, pp. 342-35, 2018.

[34] J.D. Kim and Y. Hwang, A study of mobile internet user's service quality perceptions from a user's utilitarian and hedonic value tendency perspectives, Information Systems Frontiers, vol. 14, no. 2, pp. 1-13, 2010. 
[35] K.C. Lee and N. Chung, Understanding factors affecting trust in and satisfaction with mobile banking in Korea: A modified DeLone and McLean's model perspective, Interacting with Computers, vol. 21, no. 5, pp. 85-392, 2009.

[36] G. G. Lee and H.F. Lin, Customer perceptions of e-service quality in online shopping, International Journal of Retail \& Distribution Management, vol. 33, no. 2, pp. 161-176, 2005.

[37] C.W. Leung, S.C. Chi-Fai, F. Chung, and G. Ngai, A probabilistic rating inference framework for mining user preferences from reviews. World Wide Web, vol. 14, pp. 187-215, 2011.

[38] T.F. Liao, Interpreting Probability Models: Logit, Probit, and Other Generalized Liner Models. London: Sage Publication, 1994

[39] H.F. Lin, An empirical investigation of mobile banking adoption: The effect of innovation attributes and knowledge based trust, International Journal of Information Management, vol. 31, pp. 252-260, 2010

[40] A. Lipsman. (2014, June) Major mobile milestones in may: Apps now drive half of all time spent on digital. Comscore. [Online]. Available: https://www.comscore.com/Insights/Blog/Major-Mobile-Milestones-in-MayApps-Now-Drive-Half-of-All-Time-Spent-on-Digital

[41] A. Mollen and $\mathrm{H}$. Wilson, Engagement, telepresence and interactivity in online consumer experience: Reconciling scholastic and managerial perspectives, Journal of Business Research, vol. 63, no. 9-10, pp. 919925, 2010.

[42] M.M. Montoya-Weiss, G.B. Voss and D. Grewal, Determinants of online channel use and overall satisfaction with a relational multichannel service provider, Journal of the Academy of Marketing Science, vol. 31, pp. 448458, 2003.

[43] D. Morgan, Focus Groups as Qualitative Research. London, New Delhi: Sage, Thousand Oaks, 1997.

[44] F.F.H. Nah, W. Hong, L.Q. Chen, and H.H. Lee, Information search patterns in ecommerce product comparison services, Journal of Database Management, vol. 21no. 2, pp. 26-40, 2010.

[45] N.G. Nayebi and A. Abran, A systematic literature review: Opinion mining studies from mobile app store user reviews, Journal of Systems and Software, vol. 125, pp. 207-219, 2016.

[46] K. Peng, Y. Chen and K. Wen, Brand relationship, consumption values and branded app adoption, Industrial Management and Data Systems vol. 114, no. 8, pp. 1131-1143, 2014

[47] T. Peters, O. Tona and A. Popovi c, How system quality influences mobile BI use: The mediating role of engagement, International Journal of Information Management, vol. 36, no. 5, pp. 773-783, 2016.

[48] R.S. Pindyck and D.L. Rubinfeld, Econometric Models and Economic Forecasts, third ed. New York: McGrawHill, 1991.

[49] P.M. Podsakoff, S.B. MacKenzie, J.Y. Lee, and N.P. Podsakoff, Common method biases in behavioral research: a critical review of the literature and recommended remedies, Journal of Applied Psychology, vol. 88, no. 5 , pp. 879-903, 2003

[50] G. Said, Understanding knowledge management system antecedents of performance impact: Extending the task-technology fit model with intention to share knowledge construct, Future Business Journal, vol. 1, no. 1/2, pp. 75-87, 2015.

[51] J. Santos, E-service quality: a model of virtual service quality dimensions, Managing Service Quality, vol. 13, no. 3, p. 233, 2003.

[52] E. Shove and M. Pantzar, Consumers, producers and practices - understanding the invention and reinvention of nordic walking, Journal of Consumer Culture, vol. 5, no. 1, pp. 43-64, 2005

[53] Statistica. (2017) The number of smartphone users in India. Statista. [Online]. Available: https://www.statista.com/statistics/467163/forecast-of-smartphone-users-in-india/

[54] J. Stevens, Applied Multivariate Statistics for the Social Sciences, 5th ed. London: Press, 2002.

[55] A. Vance, C. Elie-Dit-Cosaque and D. Straub, Examining trust in information technology artifacts: the effects of system quality and culture, Journal of Management Information Systems, vol. 24, no. 4, pp. 73-100, 2008.

[56] L.R. Vijayasarathy and J.M. Jones, Print and Internet catalog shopping: assessing attitudes and intentions, Internet Research, vol. 10, no. 3, p. 191, 2000

[57] J.D. Wells, J.S. Valacich and T.J. Hess, What signal are you sending? How website quality influences perceptions of product quality and purchase intentions, MIS Quarterly, vol. 35, no. 2, pp. 373-396, 2011.

[58] M.S. Yadav and R. Varadarajan, Interactivity in the electronic marketplace: an exposition of the concept and implications for research, Journal of the Academy of Marketing Science, vol. 33, no. 4, pp. 585-603, 2005.

[59] Z. Yang and M. Jun, Consumer perception of e-service quality: From internet purchaser and non purchaser perspectives, Journal of Business Strategies, vol. 19, no. 1, pp. 19-41, 2002.

[60] T. Zhou, Understanding continuance usage intention of mobile internet sites, Universal Access in the Information Society, vol. 13, no. 3, pp. 329-337, 2014. 


\section{Appendix A: Measurement Scale and Items}

\begin{tabular}{|c|c|c|c|}
\hline Construct & & Items & Source \\
\hline \multirow{6}{*}{$\begin{array}{l}\text { Visual } \\
\text { design (VIS) }\end{array}$} & VIS1 & The mobile app has appealing colors and fonts. & $\begin{array}{l}\text { Adapted from Kim } \\
\text { and Nah (2011) }\end{array}$ \\
\hline & VIS2 & $\begin{array}{l}\text { The color combination of the background is appealing } \\
\text { to me. }\end{array}$ & \\
\hline & VIS3 & I refer to the images section, posted by bank & \\
\hline & VIS4 & $\begin{array}{l}\text { I like the way, information is structured on the mobile } \\
\text { app. }\end{array}$ & \\
\hline & VIS5 & The mobile app is visually attractive. & \\
\hline & VIS6 & The graphics displayed on the mobile app are engaging & \\
\hline \multirow{7}{*}{$\begin{array}{l}\text { Information } \\
\text { design (INF) }\end{array}$} & INF1 & $\begin{array}{l}\text { The mobile app provides me with relevant information } \\
\text { to my needs. }\end{array}$ & $\begin{array}{l}\text { Adapted from Peters } \\
\text { et al. (2016)) }\end{array}$ \\
\hline & INF2 & The mobile app provides with accurate information. & \\
\hline & INF3 & The mobile app have a detailed menu option & \\
\hline & INF4 & $\begin{array}{l}\text { The mobile app have details of major touch points, to } \\
\text { contact the bank }\end{array}$ & \\
\hline & INF5 & The mobile app provides with a branch locator option & \\
\hline & INF6 & $\begin{array}{l}\text { The mobile app calculates discounts and extra charges } \\
\text { instantaneously. }\end{array}$ & \\
\hline & INF7 & $\begin{array}{l}\text { The mobile app provides a dedicated account for all my } \\
\text { transactions. }\end{array}$ & \\
\hline \multirow{5}{*}{$\begin{array}{l}\text { Navigational } \\
\text { design (NAV) }\end{array}$} & NAV1 & $\begin{array}{l}\text { The mobile app has a navigation bar, which allows me } \\
\text { to scan through the entire page in one go }\end{array}$ & $\begin{array}{l}\text { Adapted from } \\
\text { Chang et al. (2015 }\end{array}$ \\
\hline & NAV2 & The mobile app provides links to other site pages. & \\
\hline & NAV3 & $\begin{array}{l}\text { The mobile app provides a dynamic filter options for } \\
\text { making choices. }\end{array}$ & \\
\hline & NAV4 & The mobile app provides a feature of keyword search & \\
\hline & NAV5 & $\begin{array}{l}\text { The payment page interface of the mobile app is easy } \\
\text { to navigate. }\end{array}$ & \\
\hline \multirow{5}{*}{$\begin{array}{l}\text { Collaboration } \\
\text { design }\end{array}$} & COLL1 & $\begin{array}{l}\text { Using the mobile app provides me with cash back } \\
\text { options. }\end{array}$ & $\begin{array}{l}\text { Adapted from } \\
\text { Kapoor et al. (2018) }\end{array}$ \\
\hline & COLL2 & $\begin{array}{l}\text { The mobile app has tie-ups with other e-commerce } \\
\text { players such as Uber etc. }\end{array}$ & \\
\hline & COLL3 & $\begin{array}{l}\text { Using the mobile app provides incentive every time, an } \\
\text { order is placed. }\end{array}$ & \\
\hline & COLL4 & $\begin{array}{l}\text { The mobile app provides me with coupons, to be used } \\
\text { at a later stage. }\end{array}$ & \\
\hline & COLL5 & I enjoy loyalty discounts, for using the mobile app. & \\
\hline \multirow{5}{*}{$\begin{array}{l}\text { Service } \\
\text { quality (SER) }\end{array}$} & SER1 & $\begin{array}{l}\text { The mobile banking app provides with multiple touch } \\
\text { points to connect with the bank }\end{array}$ & $\begin{array}{l}\text { Adapted from Clemes } \\
\text { et al (2013) }\end{array}$ \\
\hline & SER2 & $\begin{array}{l}\text { The mobile app allows me to raise service requests } \\
\text { through the mobile app }\end{array}$ & \\
\hline & SER3 & $\begin{array}{l}\text { I get response to most of my queries and requests } \\
\text { through the mobile banking app }\end{array}$ & \\
\hline & SER4 & $\begin{array}{l}\text { All service related issues are listed in the mobile } \\
\text { banking app }\end{array}$ & \\
\hline & SER5 & $\begin{array}{l}\text { The mobile banking app provides me with personalized } \\
\text { service offerings }\end{array}$ & \\
\hline \multirow{5}{*}{ Login time (LT) } & LT1 & $\begin{array}{l}\text { My mobile banking app allows me to login to my } \\
\text { account in no time }\end{array}$ & $\begin{array}{l}\text { Developed from pre } \\
\text { study }\end{array}$ \\
\hline & LT2 & The user login process is not a time consuming task & \\
\hline & LT3 & $\begin{array}{l}\text { There are multiple level of authentication in order to } \\
\text { login to my account }\end{array}$ & \\
\hline & LT4 & Logging-in to my account is a simple process & \\
\hline & LT5 & I prefer login options that are less time consuming & \\
\hline
\end{tabular}

